\title{
Multi-layer infographic model of the construction reorganization in cyberphysics
}

\author{
Vitaly Chulkov ${ }^{1}$, Alexey Yurgaytis ${ }^{1, *}$ \\ ${ }^{1}$ Moscow State University of Civil Engineering, Yaroslavskoye Sh., 26, Moscow 129337, Russia
}

\begin{abstract}
Today, cyberphysics is considered as an interdisciplinary science and one of the important directions of modern technical development in the reorganization of the construction industry. Initially, the term "cyberphysics" meant technical systems with computational tools embedded in them. In these systems, the human operator used different channels of information transfer in the design and management processes. Over time, in the framework of the scientific and technical direction of "cyberphysics", the problems of ensuring its own state space and its parameters began to be considered. In the article, the concepts of homeostat (stable state of the building system) and an intelligent building system have been introduced and formally defined, which are used in the quantitative assessment of the quality of building systems of design and management. As the result of research, the practical task of developing an apparatus for infographic modeling has been set, the application of which would become the basis for technical regulation in certain segments of innovative technologies for construction reorganization (for example, in the housing and communal complex of the Russian Federation).
\end{abstract}

\section{Introduction}

The construction system is a material and mental activity social and technical object, in relation to which it is possible to control the processes of changing the values of its parameters. This is a finite set of functional components and the relations between them, allocated in accordance with a specific goal within a certain time interval (according to AA Volkov). A cyber-physical building system is a finite set of functional components integrated into physical and mental processes of computing resources, as well as relations between them, allocated in accordance with a specific goal within a certain time interval.

Cyber-physical systems (CPS) are designed to ensure close communication and coordination between computational and physical resources, the harmonious coexistence of traditional engineering models (organizational-technological, construction, mechanical, electrical, biological, socio-economic, etc.) and computer models. At different stages of its development, CPS manifested itself as embedded real-time systems, distributed computing systems, automated control systems for technical processes and objects, wireless sensor networks, etc.

*Corresponding author: vitolch@gmail.com , aljurgaitis@gmail.com 
Modern CPS have much in common with the structures implemented through the Internet of Things (IoT), Industry 4.0, the Industrial Internet of Things, Machine-toMachine Interaction (M2M), fog and cloud computing. But the listed examples of technical means in no way limit the idea of CPS. For these complex systems, new cybernetic approaches to modeling are required, since it is the models (and, in particular, infographic models) that are rightly considered to be central to science and engineering.

The Acatech German Academy already speaks (2012) about the future of national cyber-physical platforms, including the Internet of people, the Internet of things and the Internet services (see the diagram below - fig. 1).

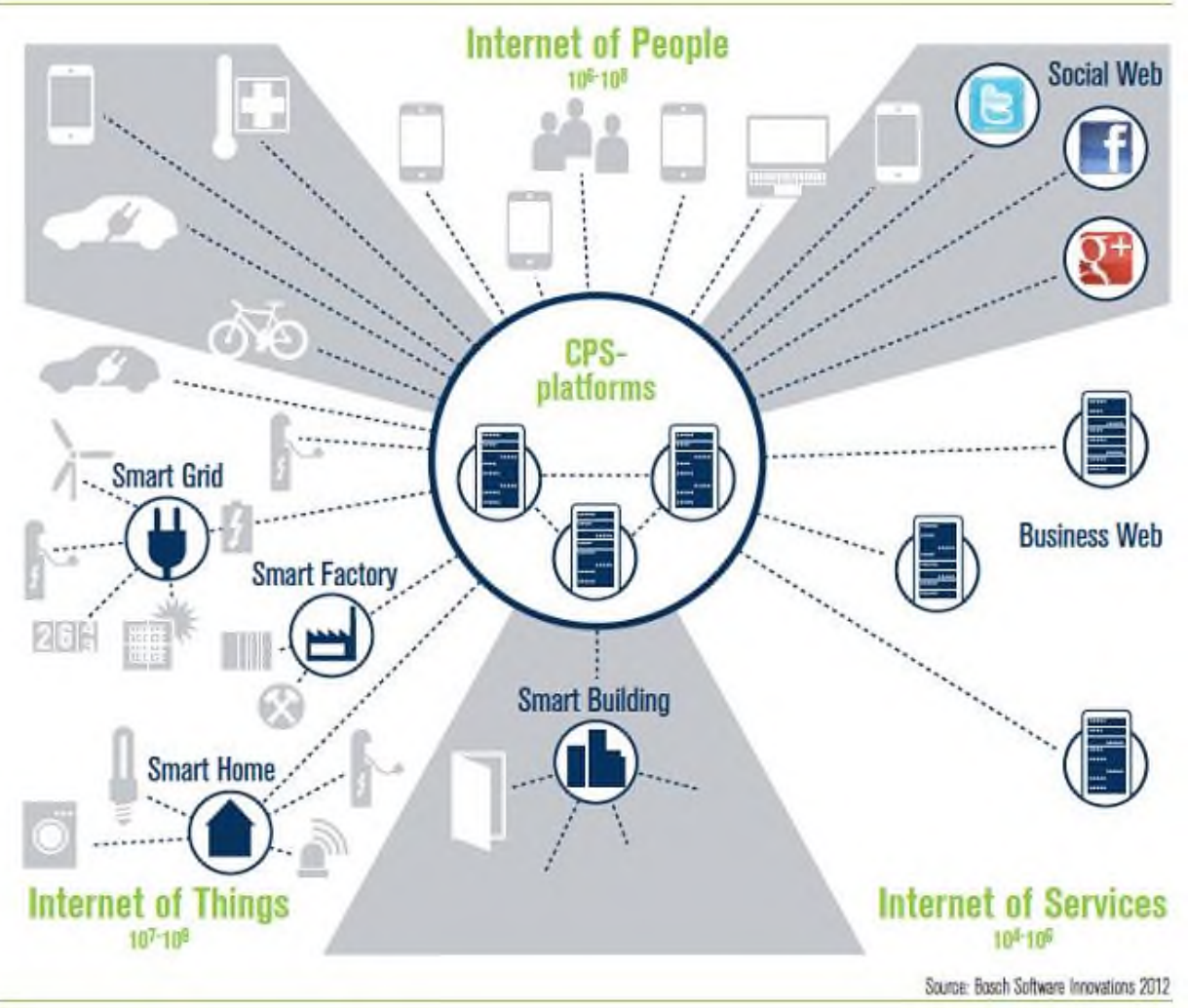

Fig. 1. Future of national cyber-physical platforms

Analysis of the problems of cyberphysics in engineering areas of activity (and in particular - the construction industry), as well as reorganization (as a fundamental process of developing activities in key sectors of the economy) and efficiency in this regard, the construction industry is devoted to the publication of numerous foreign and domestic researchers (Boccaletti S., Grebogi C., Lai Y.C. [1], Clarke E.M., Grumberg O., Jha S., Lu Y., Veith H. [2], Rabitz H. [3, 7], Xiao J.H., Hu G., Gao J.H. [4], Boccaletti S., Pecora L., Pelaez A. [5], Ortega R., van der Schaft A., Mareels I., Maske B. [6], Sontag E., Kholodenko B.N., Kiyatkin A., Bruggeman F., Westerhoff H., Hoek J. [8], Cataldo A., Lee E.A., Liu X., Matsikoudis E., Zhen G.H. [9], Huang H.M., Tidwell T., Gill C., Lu C., Gao X., Dyke S. [10], Lee E.A., Seshia S.A. [11, 17], Casciati S., Chen Z.C. [12], Hackmann G, Guo W, Yan G, Sun Z., Lu C., Dyke S. [13], Dragos K., Smarsly K. [14], Bhuiyan M.Z.A., Wu J., Wang G., Cao J., Jiang W. [15], Yuan X., Anumba C.J., Parfitt M.K. [16], Tabuada T. [18], Zaborovsky V.S., Lukashin A.A., Mulyukha V.A., Medvedev U., Fradkov A.L., Tsirlin A.M., Volkov A.A., Chulkov V.O., Chulkov G.O., Rakhmonov E.K., Kazaryan 
R.R., Fakhratov M.A., Kuzina O.N., Tolstova K.N., Kotov E.D., Chulkov V.O., Chulkov G.O., and others).

\section{Materials and Methods}

The main method of scientific research was chosen visual-figurative multi-layer infographic modeling of organizational and technological features of the construction reorganization in cyberphysics of the housing and communal complex. The authors justify the choice of such modeling by analyzing the characteristics of the current state of the organization of the urban housing and communal complex:

- citizens cannot choose who will provide them services;

- citizens cannot refuse to purchase the services provided to them;

- quality of the services provided, as a rule, is not evaluated in quantitative terms;

- citizens do not understand the mechanism for assessing the quality of many housing and communal services.

Two structures are fundamental in the stated scientific research:

- distinction between technical and medical cybernetics, each of which has its own application area (Fig. 2);

- The structure of the "graph-spider" construction reorganization (Fig. 3).

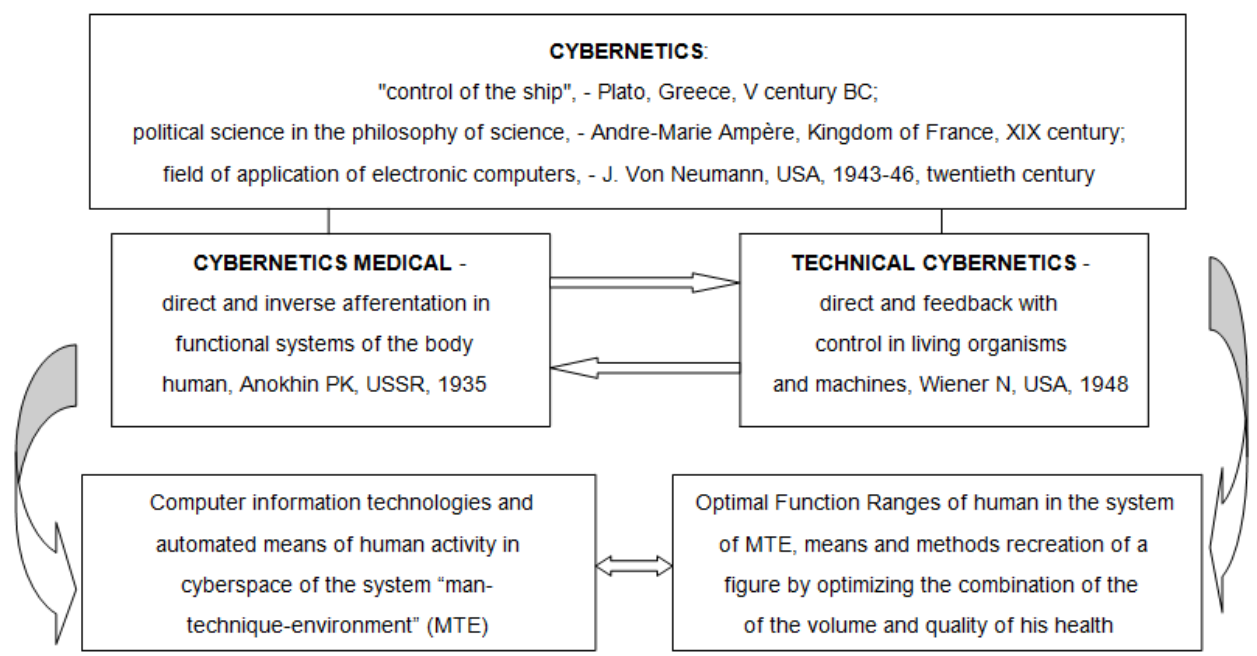

Fig. 2. Difference and connection of technical and medical cybernetics (Chulkov VO, 2016) 


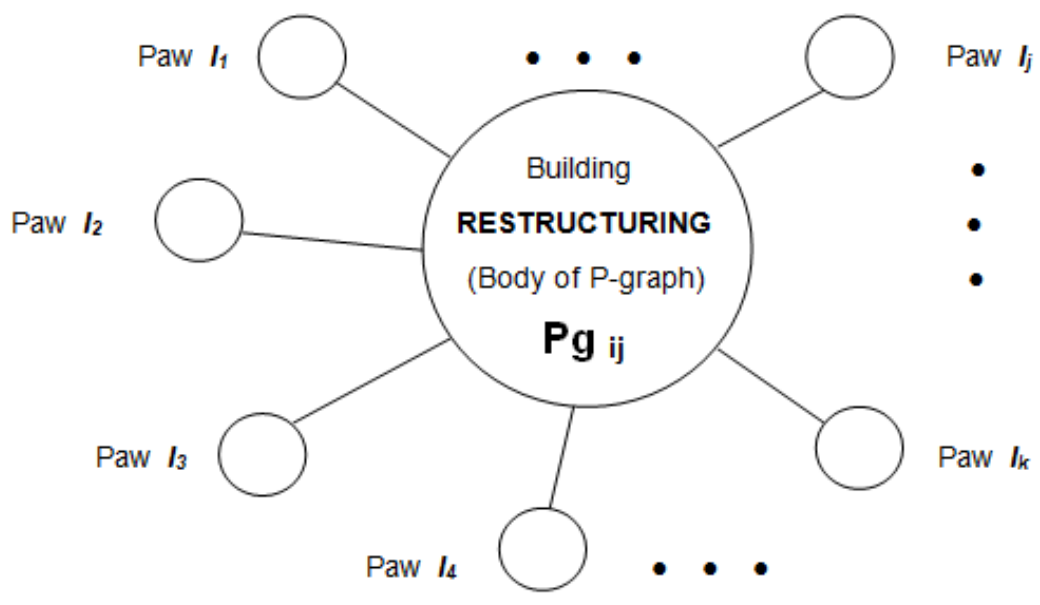

Fig. 3. Structure of a single-layer P-graph of a construction reorganization (Chulkov VO, 2017)

The first of these structures is an indirect reminder that in the modern system "mantechnic-environment, MTE" priority components are man (medical cybernetics) and the products of his thinking, implemented in labor productive activity (technical cybernetics). The habitat is, as it were, the context of these components, although it is precisely this that determines the very possibility of the existence of man and technic.

The second structure requires a more detailed explanation.

The algebraic model of a P-graph (P-graph by Efimova S.M.) differs from the Codd EF model and allows you to create formal descriptions for manipulating data based on a firstorder predicate calculus with tuple terms. This allows you to manipulate unformalized relationships. The body of the P-graph corresponds to the name of the elementary information unit. Each paw of a P-graph is assigned a natural number (foot number or its "tag"). P-graphs can be "linked" with each other by those paws that have at least one identical mark in their tagging sets. Such a linkage (both in single-layer and multi-layer infographic models) allows one to introduce a relation between specific values belonging to different elementary information units. The scheme of a multi-level network structure can be represented as a set of dependencies that define a certain network structure of a complex functional database object. The domain is assigned a $\mathrm{P}$-graph, and the tuple and the relation are assigned a network of P-graphs. A P-graph's pad can be matched with both a specific attribute value and a whole tuple of some relation.

\section{Results and Discussion}

The presented material considers two types of topology for transferring an information object from layer to layer of a multi-layer infographic model of a construction reorganization:

- without changing the status of the transferred object (for example, the P-graph paw of one model ply corresponds to the P-graph of another model layer); this kind of topology is called a "cylinder" (Fig. 4);

- with a change in the status of the transferred object (for example, the P-graph paw of one model layer corresponds to the P-graph body of another model layer); This kind of topology is called "cone" (Fig. 5). 


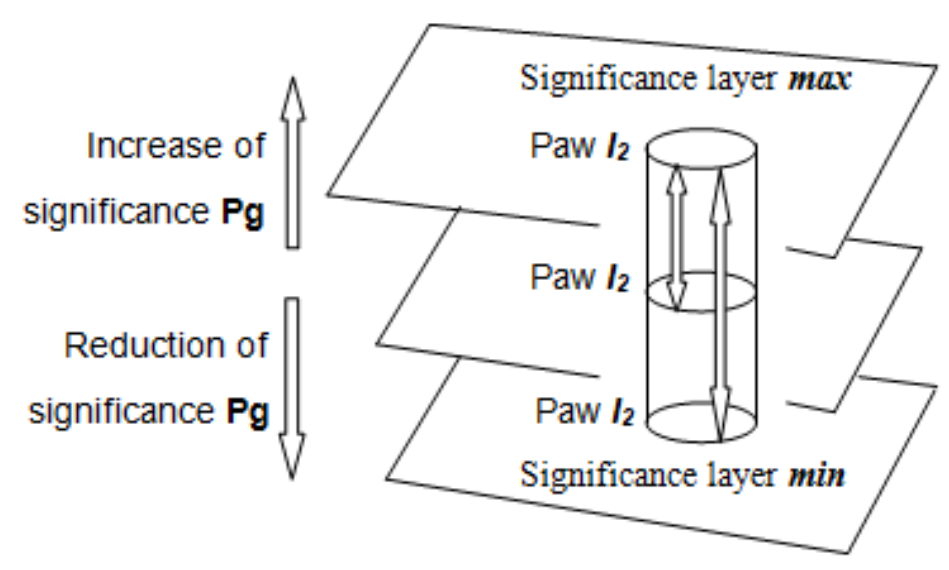

Fig. 4. Model of the topology lij $\leftrightarrow$ lij (transfer of an object from one layer to another layer without changing the status of the object, with the location of the layers according to their significance for the researcher), the conventional name of this model is "cylinder" (Chulkov VO, 2018)

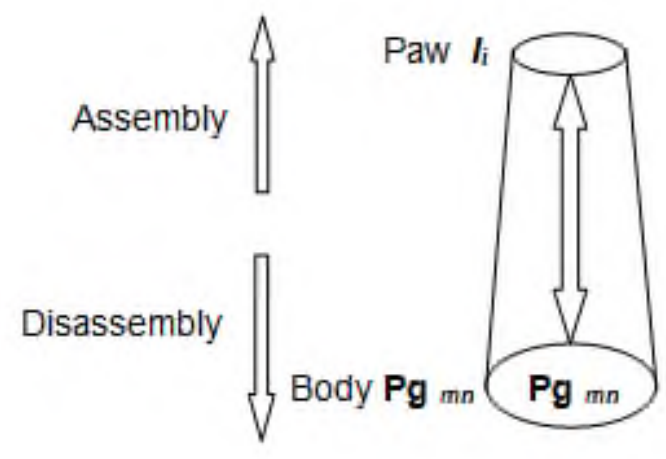

Fig. 5. Model of the topology lij $\leftrightarrow$ Pgij (transfer of an object from one layer to another with a change in the status of the object), the conventional name of this model is "cone" (Chulkov VO, 2018)

The use of the proposed topology models ("cylinder" and "cone") in their various combinations makes it possible to form a variety of infographic models of the construction reorganization in cyberphysics of the housing and communal complex (Fig. 6). 


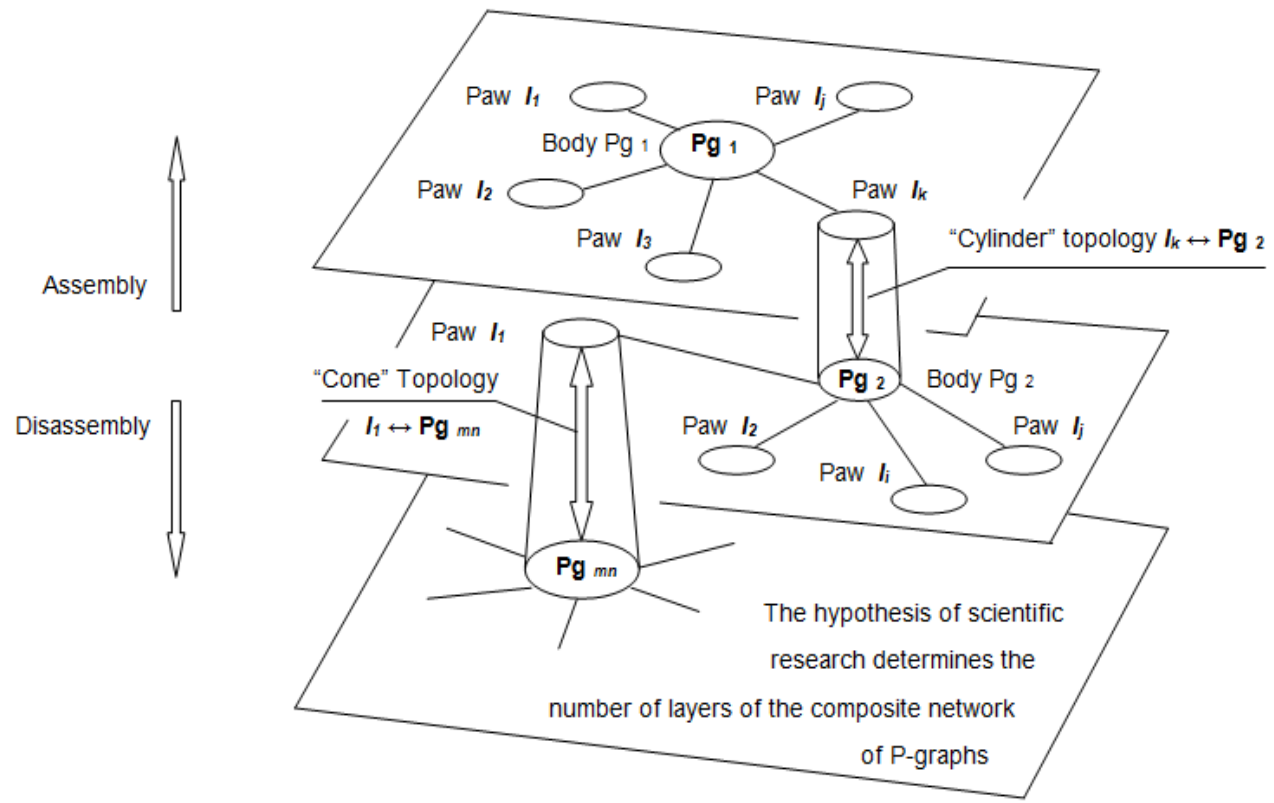

Fig. 6. A variety of use of topologies "cylinder" and "cone" in different combinations in a multilayered infographic model (Chulkov VO, 2018)

In single-layer infographic models of the construction reorganization in the cyberphysics of the housing and communal complex (Fig. 6), U-graphs can be "linked" to each other by those legs that have at least one identical label in their marking sets. This allows the formation of single-layer networks of concatenated P-graphs, which, if necessary, can be converted into their multilayer models.

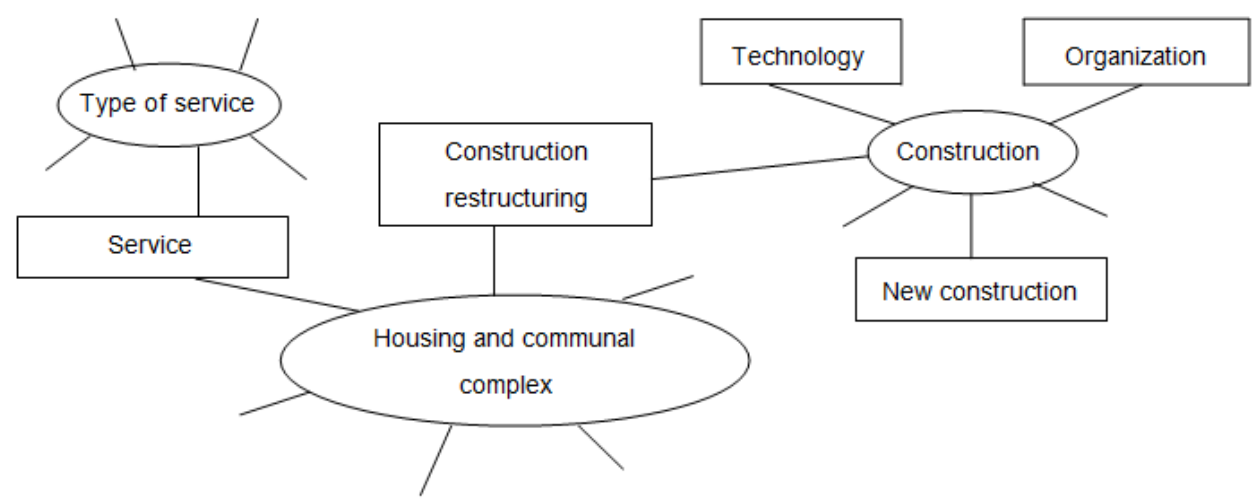

Fig. 7. Single-layer network of flat GHGs (Chulkov VO, 2018)

The result of a scientific study of the possibilities of building and using single-layer and multi-layered infographic models of the construction reorganization in cyberphysics of the housing and utility complex are private and complex indicators of reliability and efficiency. The most generalizing of them should be considered the readiness ratio of the construction industry (the ratio of the time of failure-free organizational and technological reorganization to the full period of the observation period). The average statistical values of the ranges of the availability factor for: 
- technical means of mechanization and transportation were determined: 0.86-0.92;

- material resources and components: 0.80-0.85;

- labor resources: 0.78-0.83.

\section{Conclusion}

Using the theory of multipoint logic and the practice of infographic modeling, single-layer and multi-layer infographic models of building reorganization in the housing and utilities complex at all four stages of this process (device, disorganization, reorganization and coorganization) are structured. The most interesting stage is the construction reorganization, which has a special relevance and requires new original approaches and concepts of development. A further direction of the scientific study of construction reorganization is the identification of traditional and innovative types of reorganization with the subsequent study of the typical properties and characteristics of each of them. Currently, the most relevant type of modern construction reorganization for the housing and communal complex of the Russian Federation is renovation.

\section{References}

1. M. Z. A. Bhuiyan, J. Wu, G. Wang, J. Cao, W. Jiang, IEEE Transactions on Industrial Informatics, 12(6), 2103-2114 (2016)

2. X. Yuan, C. J. Anumba, M. K. Parfitt, Automation in Construction, 66, 1-14 (2016)

3. D. V. Topchiy, A. Ya. Tokarskii, Science and Business, 10(76), 15-19 (2017)

4. D. V. Topchiy, V. A. Skakalov, Prospects of Science, 10(97), 44-50 (2017)

5. A. A. Afanasyev, Academia. Architecture and construction, 2, 113-118 (2016)

6. P. P. Oleinik, Scientific Review, 14, 239-243 (2016)

7. I. L. Abramov, A. A. Lapidus, E3S Web of Conferences, 33, 03066 (2018)

8. I. Potekhin, V. Mischenko, A. Mottaeva, A. Zheltenkov, E3S Web of Conferences, 33, 03020 (2018) doi: 10.1051/e3sconf/20183303020

9. E. Vasilyeva, E3S Web of Conferences, 33, 03048 (2018)

10. V. A. Pukhkal, A. B. Mottaeva, Magazine of Civil Engineering, 81(5), 203-212 (2018) doi: 10.18720/MCE.81.20

11. A. Lapidus, I. Abramov, MATEC Web of Conferences, 193, 05033 (2018)

12. A. Lapidus, I. Abramov, IOP Conf. Ser.: Material Science, 365, 062002 (2018)

13. I. Abramov, A. Stepanov, I. F. Ibrahim, MATEC Web of Conferences, 117, 00001 (2017)

14. K. Tolstova, V. Chulkov, MATEC Web of Conferences, 117, 00169, (2017) DOI: 10.1051/matecconf/201711700169

15. E. Kotov, V. Chulkov, G. Chulkov, IOP Publishing, IOP Conf. Series: Materials Science and Engineering, 365, 022003(2018). DOI: 10.1088/1757899X/365/2/022003

16. P. Oleinik, A. Yurgaytis, MATEC Web of Conferences, 117, 00130, (2017), https://doi.org/10.1051/matecconf/201711700130 
17. D. Topchiy, A. Shatrova, A. Yurgaytis, MATEC Web of Conferences, 193, 05032, (2018), https://doi.org/10.1051/matecconf/201819305032

18. P. Oleinik, A. Yurgaytis, MATEC Web of Conferences, 193, 05010, (2018), https://doi.org/10.1051/matecconf/201819305010 